\title{
Inkontinensia Urin pada Lanjut Usia di Panti Werdha Provinsi Riau
}

\section{Urinary Incontinence among Institutionalized Elderly in Riau Province}

\author{
Desby Juananda ${ }^{1}$, Dhany Febriantara ${ }^{2}$ \\ ${ }^{1}$ Kelompok Jabatan Fungsional (KJF) Anatomi, Fakultas Kedokteran Universitas Riau \\ ${ }^{2}$ Fakultas Kedokteran Universitas Riau
}

\begin{abstract}
ABSTRAK
Inkontinensia urin (IU) diartikan sebagai keluarnya urin tanpa disadari yang dapat diamati secara objektif, serta menimbulkan masalah sosial dan kebersihan. IU merupakan salah satu masalah kesehatan yang sering dijumpai pada lanjut usia (lansia). Pada penelitian ini akan dinilai gambaran prevalensi dan dampak IU, serta kualitas tidur pada lansia di Panti Werdha Provinsi Riau. Penelitian ini merupakan penelitian deskriptif dengan rancangan potong lintang yang dilakukan pada 30 orang lansia berusia lebih dari 60 tahun menggunakan instrumen penelitian berupa kuesioner, antara lain Incontinence Impact Questionnaire-7 (IIQ7), Urogenital Distress Inventory-6 (UDI-6), dan Pittsburgh Sleep Quality Index (PSQI). Pada penelitian ini diketahui bahwa 16 orang $(53,33 \%)$ lansia mengalami IU, dan umumnya adalah perempuan. Tipe IU yang ditemukan, antara lain tipe urgensi sebanyak 14 orang $(87,5 \%)$, tipe stres sebanyak 1 orang $(6,25 \%)$ dan tipe luapan sebanyak 1 orang $(6,25 \%)$. IU diketahui berdampak pada aktivitas fisik $(44,44 \%)$, perjalanan $(44,44 \%)$ dan kesehatan emosional $(11,12 \%)$. Lansia yang mengalami IU memiliki kualitas tidur yang tidak baik (100\%) dan waktu tidur yang singkat (68,75\%). Penelitian ini menunjukkan bahwa prevalensi IU pada lansia di Panti Werdha Provinsi Riau cukup tinggi dengan distribusi terbanyak adalah tipe urgensi. IU diyakini sangat berdampak pada aktivitas fisik, emosi dan kualitas tidur.
\end{abstract}

Kata kunci: inkontinensia urin, kualitas tidur, lanjut usia

\begin{abstract}
Urinary incontinence (UI) is defined as involuntary loss of urine that can be demonstrated objectively, and of social and hygienic problems. UI is a medical problem that can commonly be seen in elderly. The aim of this study was to identify the prevalence, the distribution of the type, the related impact of UI, and also the sleep quality among elderly in Riau institutional care. This is a descriptive study with cross sectional design. Thirty participants above 60 years old living in institutional care were interviewed using the Incontinence Impact Questionnaire-7 (IIQ-7), the Urogenital Distress Inventory-6 (UDI-6), and the Pittsburgh Sleep Quality Index (PSQI). We obtained 16 subjects (53,33\%) suffering from UI especially in women. The distribution of the type is 14 subjects (87,5\%) with urge incontinence, 1 subject (6,25\%) with stress incontinence and 1 subject (6,25\%) with overflow incontinence. We found that UI impaired the physical activity $(44,44 \%)$, travelling $(44,44 \%)$ and mental health $(11,12 \%)$. We also found that subjects with UI reported worse sleep quality (100\%), and spending short time in bed (68,75\%). This study shows that the prevalence of $\mathrm{UI}$ in Riau institutional care is excessively; while the distribution of the type is urge incontinence generally. UI seems to impact physical activity, mental health, and sleep quality.

Keywords: elderly, sleep quality, urinary incontinence
\end{abstract}

Korespondensi : Desby Juananda, email: desbyjuananda@gmail.com

Artikel info: Online published first 14 September 2017.

DOI: https://doi.org/10.26891/jkm.v1i1.2017.20-24

Copyright @ 2017 Authors. This is an open access article distributed under the terms of the Creative Commons Attribution-NonCommercial 4.0 International License (http://creativecommons.org/licenses/by-nc/4.0/), which permits unrestricted non-commercial use, distribution, and reproduction in any medium, provided the original author and source are properly cited. 
Inkontinensia urin (IU) merupakan salah satu masalah kesehatan yang sering dijumpai pada lansia. Hal tersebut jarang disampaikan oleh pasien maupun keluarga karena dianggap memalukan (tabu) atau wajar terjadi pada lansia sehingga tidak perlu diobati. IU dinilai bukan sebagai penyakit, melainkan suatu gejala yang dapat menimbulkan berbagai gangguan kesehatan, sosial, psikologi serta dapat menurunkan kualitas hidup. IU merupakan keluarnya urin tidak disadari dan pada waktu yang tidak diinginkan (tanpa memperhatikan frekuensi dan jumlah) yang mengakibatkan masalah sosial dan higienisitas penderitanya. ${ }^{1}$ Prevalensi IU pada perempuan di dunia berkisar antara 10-58\%. Menurut Asia Pasific Continence Advisor Board (APCAB), prevalensi IU pada perempuan Asia adalah 14,6\%, dimana sekitar 5,8\% berasal dari Indonesia. ${ }^{1}$ Survei IU oleh Rumah Sakit Umum Dr. Soetomo (2008) pada 793 pasien menunjukkan bahwa prevalensi IU pada perempuan 6,79\%, sedangkan pada laki-laki 3,02\%. Survei lainnya oleh Rumah Sakit Umum Pusat Nasional Cipto Mangunkusumo (2003) pada 179 lansia menunjukkan bahwa angka kejadian IU tipe stres pada laki-laki $20,5 \%$, sedangkan pada perempuan $32,5 \%$. Hal tersebut menunjukkan bahwa prevalensi IU pada perempuan lebih tinggi daripada laki-laki. ${ }^{2}$

Proses menua diyakini sebagai salah satu faktor predisposisi terjadinya IU. ${ }^{2}$ Penuaan menyebabkan banyak perubahan anatomis dan fisiologis organ urogenital bagian bawah, antara lain fibrosis, atrofi mukosa, perubahan vaskularisasi submukosa dan menipisnya lapisan otot yang menggangu kontraktilitas dan mudah terbentuk trabekulasi hingga divertikel. Hal ini akan menyebabkan posisi kandung kemih prolaps sehingga melemahkan tekanan. ${ }^{3}$ Risiko IU akan meningkat pada perempuan dengan obesitas, riwayat histerektomi, infeksi urogenital dan trauma perineal, serta melahirkan pervaginam. Pada lansia yang dirawat di panti werdha, IU sering berkaitan dengan gangguan mobilitas, demensia, depresi, stroke, diabetes mellitus dan Parkinson. Faktor risiko IU lainnya yang dapat dimodifikasi, antara lain infeksi saluran kemih, keterbatasan aktivitas fisik dan faktor gangguan lingkungan. ${ }^{3}$

Inkontinensia urin mempunyai dampak medik, psikososial dan ekonomik. ${ }^{1,2}$ Beberapa kondisi yang sering menyertai IU, antara lain kelainan kulit dan gangguan tidur, hingga dampak psikososial dan ekonomik, seperti depresi, mudah marah, terisolasi, hilang percaya diri, pembatasan aktifitas sosial, dan besarnya biaya rawatan. ${ }^{4}$ Kualitas tidur yang menurun disebabkan oleh lingkungan tidur yang tidak nyaman, terbangun malam hari untuk berkemih, dan stres. Hal tersebut menyebabkan penurunan konsentrasi, mudah marah dan sulitnya mengambil keputusan..$^{3,4}$

Data tentang IU pada lansia di Indonesia belum lengkap, sehingga prevalensi pasti tidak diketahui. Hal ini mungkin saja disebabkan oleh kurangnya deteksi dini oleh petugas kesehatan akibat rendahnya pengetahuan tentang tatalaksana IU. Pentingnya informasi mengenai hal tersebut melatarbelakangi perlunya dikaji dan diteliti bagaimana gambaran prevalensi dan dampak IU, serta kualitas tidur pada lansia di Panti Werdha Provinsi Riau.

\section{METODE}

Penelitian ini adalah penelitian deskriptif dengan rancangan potong lintang. Penelitian ini dilakukan pada 30 orang lansia (jompo) berusia lebih dari 60 tahun di Unit Pelaksana Teknis (UPT) Pelayanan Sosial Tresna Werdha (PSTW) Khusnul Khotimah Provinsi Riau. Penelitian ini

telah mendapatkan izin Komite Tetap Etik Penelitian Kedokteran dan Kesehatan Fakultas Kedokteran Universitas Riau No. 89/UEPKK/2015.

Pada penelitian ini digunakan berbagai instrumen penelitian berupa kuesioner, meliputi Incontinence Impact Questionnaire-7 (IIQ-7), Urogenital Distress Inventory-6 (UDI-6) dan Pittsburgh Sleep Quality Index (PSQI) yang akan ditanyakan langsung kepada responden melalui wawancara terpimpin. IIQ-7 digunakan untuk mengetahui dampak IU terhadap aktivitas fisik (item 1 \& 2), perjalanan (item 3 \& 4), hubungan sosial (item 5) dan emosional (item 6 \& 7). UDI-6 digunakan untuk mengetahui tipe IU, yaitu urgensi (item 1 \& 2), stres (item 3 \& 4) dan luapan (item 5 $\& 6$ ). PSQI digunakan untuk menilai kualitas tidur yang terdiri dari tujuh indikator penilaian, yaitu kualitas tidur subjektif, latensi tidur, durasi tidur, efisiensi tidur, gangguan tidur, penggunaan obat tidur dan keluhan pada siang hari seperti mengantuk. Tiap komponen memiliki kisaran nilai antara 0-3 dengan 0 menunjukkan tidak adanya kesulitan tidur dan 3 menunjukkan kesulitan tidur yang berat. Skor dari ketujuh komponen tersebut dijumlahkan menjadi satu skor global dengan kisaran nilai 0-21.

Seluruh variabel pada penelitian dianalisis secara proporsional dan sederhana dengan menggunakan analisis univariat, kemudian data disajikan dalam bentuk tabel dan diagram. Cara perhitungan dilakukan dengan menggunakan rumus, sebagai berikut:

Persentase: $\frac{\mathrm{F}}{\mathrm{N}} \times 100 \%$

Keterangan

$\mathrm{F}$ = Frekuensi

$\mathrm{N}$ = Jumlah

\section{HASIL}

\section{Inkontinensia urin (IU) pada lansia}

Subjek penelitian dibagi menjadi dua kelompok, yaitu lansia yang mengalami IU dan tanpa IU. Berdasarkan penggolongan umur, lansia dibagi menjadi tiga kelompok umur, yaitu elderly (60-75 tahun), old (75-90 tahun), very old (>90 tahun), sedangkan berdasarkan jenis kelaminnya lansia digolongkan menjadi laki-laki dan perempuan. Pada penelitian ini dijumpai bahwa IU dialami oleh 53,33\% lansia yaitu pada kelompok umur elderly (81,25\%) dan terutama perempuan $(56,25 \%)$ (tabel 1$)$.

Tabel 1. Karakteristik Lansia Berdasarkan Umur dan Jenis Kelamin

\begin{tabular}{|c|c|c|}
\hline \multirow[b]{2}{*}{ Karakteristik Lansia } & \multicolumn{2}{|c|}{ Inkontinensia Urin (IU) } \\
\hline & $\begin{array}{l}\text { Tidak IU } \\
45,66 \%(n=14)\end{array}$ & $\begin{array}{l}\text { IU } \\
53,33 \%(n=16)\end{array}$ \\
\hline \multicolumn{3}{|l|}{ Umur (\%) } \\
\hline - Elderly (60-74 & $64,28(9)$ & $81,25(13)$ \\
\hline tahun) & $35,72(5)$ & $18,75(3)$ \\
\hline $\begin{array}{l}\text { Old }(75-90 \\
\text { tahun) } \\
\text { Very old ( }>90 \\
\text { tahun) }\end{array}$ & - & - \\
\hline Jenis Kelamin (\%) & & \\
\hline - Laki-laki & $42,86(6)$ & $43,75(7)$ \\
\hline - $\quad$ Perempuan & $57,14(8)$ & $56,25(9)$ \\
\hline
\end{tabular}


Berdasarkan kuesioner UDI-6, tipe IU terbanyak adalah urgensi $(87,5 \%)$, bila dibandingkan stres $(6,25 \%)$ dan luapan (6,25\%) (tabel 2). Pada penelitian ini, IU berdampak terhadap aktivitas dan emosi hanya pada $56,25 \%$ dari total seluruh lansia yang mengalami IU. Berdasarkan kuesioner IIQ-7, IU umumnya berdampak pada aktivitas fisik $(44,44 \%)$ dan perjalanan $(44,44 \%)$, bila dibandingkan dengan emosi (11,12\%) (tabel 3). Tidak dijumpai dampak inkontinensia urin pada hubungan sosial lansia.

Tabel 2. Tipe Inkontinensia Urin pada Lansia

\begin{tabular}{lll}
\hline Tipe Inkontinesia Urin & $\begin{array}{l}\text { Jumlah } \\
\text { (n) }\end{array}$ & Persentase (\%) \\
\hline Urgensi & 14 & 87,5 \\
Stres & 1 & 6,25 \\
Luapan & 1 & 6,25 \\
\hline
\end{tabular}

Tabel 3. Dampak Inkontinensia Urin pada Lansia

\begin{tabular}{lll}
\hline Dampak Inkontinensia & $\begin{array}{l}\text { Jumlah } \\
\text { Urin }\end{array}$ & Persentase (\%) \\
\hline Aktivitas fisik & 4 & 44,44 \\
Perjalanan & 4 & 44,44 \\
Hubungan sosial & - & - \\
Emosi & 1 & 11,12 \\
\hline
\end{tabular}

\section{Kualitas tidur pada lansia}

Berdasarkan kuesioner PSQI, seluruh lansia yang mengalami IU memiliki kualitas tidur tidak baik (100\%). Hal ini serupa dengan lansia yang tidak mengalami IU, dimana sebagian besar juga memiliki kualitas tidur yang tidak baik $(92,86 \%)$ (tabel 4). Pada penelitian ini, penilaian kualitas tidur dilakukan berdasarkan komponen-komponen sesuai standar PSQI (tabel 5).

Tabel 4. Kualitas Tidur pada Lansia

\begin{tabular}{lll}
\hline \multirow{2}{*}{ Kualitas Tidur } & \multicolumn{2}{l}{ Inkontinensia Urin (IU) } \\
\cline { 2 - 3 } & $\begin{array}{l}\text { Tidak IU } \\
(\mathrm{n}=14)\end{array}$ & $\begin{array}{l}\text { IU } \\
(\mathrm{n}=16)\end{array}$ \\
\hline Baik (\%) & $7,14(1)$ & - \\
Tidak baik (\%) & $92,86(13)$ & $100(16)$ \\
\hline
\end{tabular}

Tabel 5. Komponen-komponen Kualitas Tidur pada Lansia

\begin{tabular}{|c|c|c|}
\hline \multirow[b]{2}{*}{ Komponen Kualitas Tidur } & \multicolumn{2}{|c|}{ Inkontinensia Urin (IU) } \\
\hline & $\begin{array}{l}\text { Tidak IU } \\
(\mathrm{n}=14)\end{array}$ & $\begin{array}{l}\text { IU } \\
(n=16)\end{array}$ \\
\hline \multicolumn{3}{|l|}{ Kualitas tidur subjektif (\%) } \\
\hline - Sangat baik & $28,57(4)$ & - \\
\hline - Cukup baik & $50(7)$ & $62,5(10)$ \\
\hline - Cukup buruk & $14,28(2)$ & $31,25(5)$ \\
\hline - Sangat buruk & $7,15(1)$ & $6,25(1)$ \\
\hline \multicolumn{3}{|l|}{ Latensi tidur (\%) } \\
\hline - Latensi tidur $\leq 15$ menit & $57,14(8)$ & $18,75(3)$ \\
\hline Latensi tidur 16-30 menit & $21,42(3)$ & $12,5(2)$ \\
\hline - Latensi tidur 31-60 menit & $7,14(1)$ & $37,5(6)$ \\
\hline - Latensi tidur $\geq 60$ menit & $14,29(2)$ & $31,25(5)$ \\
\hline \multicolumn{3}{|l|}{ Durasi tidur (\%) } \\
\hline - Durasi tidur >7 jam & - & - \\
\hline - Durasi tidur 6-7 jam & - & - \\
\hline - Durasi tidur 5-6 jam & $7,14(1)$ & $12,5(2)$ \\
\hline - Durasi tidur $<5$ jam & $92,86(13)$ & $87,5(14)$ \\
\hline \multicolumn{3}{|l|}{ Efisiensi tidur sehari-hari (\%)* } \\
\hline - $\quad$ Efisiensi tidur $>85 \%$ & $14,28(2)$ & $6,25(1)$ \\
\hline - $\quad$ Efisiensi tidur $75-84 \%$ & - & $6,25(1)$ \\
\hline - $\quad$ Efisiensi tidur $65-74 \%$ & $21,42(3)$ & $18,75(3)$ \\
\hline
\end{tabular}

- $\quad$ Efisiensi tidur $<65 \%$

Gangguan tidur (\%)

- Tidak ada pada bulan lalu

- Kurang dari sekali dalam seminggu

- Sekali atau dua kali dalam seminggu

- Tiga kali atau lebih dalam seminggu

Penggunaan obat tidur (\%)

- Tidak ada pada bulan lalu

- Kurang dari sekali dalam seminggu

- Sekali atau dua kali dalam seminggu

- Tiga kali atau lebih dalam seminggu

Disfungsi tidur siang hari (\%)

- Tidak ada pada bulan lalu

- Kurang dari sekali dalam seminggu

- Sekali atau dua kali dalam seminggu

- Tiga kali atau lebih dalam seminggu

*) Efisiensi tidur dihitung dengan rumus sebagai berikut:

Efisiensi tidur: Durasi tidur $x 100 \%$ Jam bangun pagi - Jam tidur malam

Lansia yang mengalami IU umumnya memiliki kualitas tidur subjektif cukup baik (62,5\%), latensi tidur $\geq 60$ menit $(31,25 \%)$, durasi tidur $<5$ jam $(87,5 \%)$, efisiensi tidur sehari-hari $<65 \%(68,75 \%)$, gangguan tidur sekali atau dua kali dalam seminggu $(53,75 \%)$, penggunaan obat tidur tidak ada pada bulan lalu $(68,75 \%)$ dan disfungsi tidur siang hari juga tidak ada pada bulan lalu $(43,75 \%)$. Lansia yang tidak mengalami IU umumnya memiliki kualitas tidur subjektif sangat baik $(28,57 \%)$, latensi tidur $\leq 15$ menit $(57,14 \%)$, durasi tidur $<5$ jam $(92,86 \%)$, efisiensi tidur sehari-hari $<65 \%(64,3 \%)$, gangguan tidur kurang dari sekali dalam seminggu $(64,28 \%)$, penggunaan obat tidur tidak ada pada bulan lalu (92,85\%), dan disfungsi tidur siang hari juga tidak ada pada bulan lalu $(64,28 \%)$.

\section{DISKUSI}

Penelitian terdahulu menunjukkan bahwa lansia yang dirawat di panti werdha umumnya mengalami IU, dimana perempuan lebih rentan bila dibandingkan dengan lakilaki.5,6 Prevalensi IU diyakini meningkat seiring dengan pertambahan usia. ${ }^{2}$ Sekitar $50 \%$ lansia perempuan yang berusia lebih dari 65 tahun diyakini telah mengalami IU.7 Secara klinis, IU dibagi menjadi empat tipe, yaitu urgensi, stres, fungsional dan luber (overflow). Pada penelitian ini tipe IU terbanyak adalah urgensi, bila dibandingkan dengan stres dan luapan. Dua kelainan saluran kemih bagian bawah yang mendasari terjadinya IU persisten, yaitu: 1) kegagalan menyimpan urin pada kandung kemih akibat hiperaktif atau menurunnya kapasitas kandung kemih (lemahnya tahanan saluran keluar), dan 2) kegagalan pengosongan kandung kemih akibat melemahnya kontraksi otot detrusor atau meningkatnya tahanan aliran keluar. 
Inkontinensia urin tipe urgensi merupakan kasus tersering yang terjadi pada lansia. ${ }^{8} \mathrm{Hal}$ ini biasanya ditandai oleh ketidakmampuan menunda berkemih setelah sensasi berkemih muncul dengan manifestasi, antara lain urgensi, frekuensi dan nokturia. Faktor risiko utama IU tipe urgensi adalah pertambahan usia. ${ }^{9}$ Sebagai etiologi, usia juga selalu dikaitkan dengan faktor risiko lainnya, seperti perubahan pada saluran kemih bagian bawah, vaskuler dan susunan saraf pusat. Beberapa penelitian meyakini diabetes mellitus dapat meningkatkan risiko IU tipe urgensi akibat neuropati diabetik. ${ }^{1}$ Selain itu, infeksi saluran kemih bawah juga dapat meningkatkan risiko IU tipe urgensi dengan cara memicu hiperefleksia dari otot detrusor. 9,10

Inkontinensia urin umumnya mempunyai dampak pada aktivitas fisik, perjalanan dan kesehatan emosional. Sering kali IU dianggap sebagai hal yang memalukan, dan menyebabkan lansia menarik diri dari lingkungan sosial. ${ }^{11}$ Lansia menjadi tidak percaya diri, depresi, cemas, pemarah dan terisolasi. ${ }^{1}$ Dampak IU terhadap sosial-ekonomi dan kualitas hidup lansia telah meningkatkan jumlah lansia yang dirawat di panti werdha. ${ }^{3}$

Pada penelitian ini, kualitas tidur pada lansia yang mengalami IU dan tanpa IU umumnya tergolong tidak baik. Lansia diketahui membutuhkan waktu lebih lama untuk memulai tidur dan lebih sedikit waktu tidur nyenyaknya. ${ }^{4}$ Lansia memiliki waktu tidur yang dalam (delta sleep) lebih pendek, sedangkan tidur stadium 1 dan stadium 2 (tidur ringan) lebih lama. Lansia terbukti lebih sering terbangun pada malam hari akibat perubahan fisik karena faktor usia dan penyakit yang dialaminya sehingga kualitas tidur secara nyata akan menurun. ${ }^{12}$ Beberapa keluhan subjektif pada lansia terkait kualitas tidurnya, antara lain menghabiskan terlalu banyak waktu di tempat tidur, lebih sedikit waktu untuk tidur nyenyak, jumlah terbangun yang meningkat, memerlukan waktu lebih banyak untuk bisa tidur, kepuasan tidur kurang, keletihan sepanjang hari, serta lebih sering dan lebih lama menghabiskan waktu untuk istirahat. ${ }^{13}$

Berbagai penelitian melaporkan gangguan tidur pada lansia bersifat multifaktorial, diantaranya oleh faktor fisik, psikologis, pengaruh obat-obatan, kebiasaan tidur, dan penyakit penyerta lainnya. Kualitas tidur yang menurun pada lansia yang mengalami IU mungkin disebabkan oleh beberapa kondisi, antara lain lingkungan tidur yang tidak nyaman, terbangun pada malam hari untuk berkemih, dan stres yang dipicu oleh rasa tidak nyaman akibat IU. ${ }^{14}$ Selain itu, faktor lainnya juga perlu diperhatikan salah satunya adalah pola aktivitas pada siang hari. Lansia yang banyak beraktivitas pada siang hari akan cenderung sulit tidur pada malam hari. ${ }^{4}$

\section{SIMPULAN}

Lansia yang dirawat di Panti Werdha Provinsi Riau umumnya mengalami IU, dimana perempuan lebih berisiko bila dibandingkan dengan laki-laki. Hal ini dapat berdampak pada aktivitas fisik, perjalanan dan kesehatan emosional. Lansia yang mengalami IU memiliki kualitas tidur yang tidak baik. Lansia diketahui memiliki sedikit waktu untuk tidur nyenyak, jumlah terbangun tengah malam yang meningkat, memerlukan waktu lebih banyak untuk bisa tidur, kepuasan tidur berkurang, dan lebih lama menghabiskan waktu untuk istirahat. Pencegahan dan pengendalian faktor risiko adalah salah satu strategi untuk menurunkan morbiditas, sekaligus meningkatkan kualitas hidup pada lansia yang mengalami IU di panti werdha.
Pada penelitian selanjutnya dapat dikaji gambaran prevalensi dan dampak inkontinensia urin pada lansia yang berada di komunitas.

\section{UCAPAN TERIMA KASIH}

Penulis mengucapkan terima kasih yang sebesar-besarnya kepada Dr. dr. Dedi Afandi, D.F.M., Sp.F. selaku Dekan Fakultas Kedokteran Universitas Riau (FK UR), Prof. Dr. Almasdi Syahza, S.E., M.P. selaku Ketua Lembaga Penelitian dan Pengabdian kepada Masyarakat Universitas Riau (LPPM UR), dan Anida Asfarina, S.H. selaku Kepala UPT PSTW Khusnul Khotimah Provinsi Riau atas bimbingan dan dukungannya pada penelitian ini. Penelitian ini dibiayai oleh Penelitian Hibah FK UR (PNBP) Tahun Anggaran 2016 (No. Kontrak: 60/UN19.5.1.1.8/UPPM/2016).

\section{DAFTAR PUSTAKA}

1. Setiati S \& Pramantara IDP. Inkontinensia urin dan kandung kemih hiperaktif. Dalam: Aru WS, Bambang $S$, Idris A, Marcellus $S$ \& Siti $S$, editor (penyunting). Buku ajar ilmu penyakit dalam. Edisi ke-2. Jakarta: Pusat Penerbit Ilmu Penyakit Dalam; 2004. hlm 139299.

2. Rijal C \& Hakim S. Urinary incontinence in women living in nursing homes: prevalence and risk factors. Indones. J. Obstet. Gynecol. 2014; 2(4):193-8.

3. Cook K \& Sobeski LM. Urinary incontinence in the older adult. PSAP.2013;1-15.

4. Rahayu RA. Gangguan tidur pada usia lanjut. Dalam: Aru WS, Bambang S, Idris A, Marcellus S \& Siti S, editor (penyunting). Buku ajar ilmu penyakit dalam. Edisi ke-2. Jakarta: Pusat Penerbit IImu Penyakit Dalam; 2004. hlm 1350-6.

5. Kuchel GA \& DuBeau CE. Urinary incontinence in the elderly. Clin. J. Am. Soc. Nephrol. 2009;1-5.

6. Sumardi R, Mochtar CA, Junizaf, Santoso BI, Setiati S, Nuhonni $S A$, et al. Prevalence of urinary incontinence, risk factors and its impact: multivariate analysis from Indonesian nationwide survey. Acta Med. Indones.Indones. J. Intern. Med. 2014; 46(3):175-82.

7. Tendean HMM. Deteksi inkontinensia urin pada usia post menopause dengan menggunakan Kuesioner IIQ7 dan UDI-6. JKM. 2007; 6(2).

8. Santoso BI. Inkontinensia urin. Maj. Kedokt. Indon. 2008; 58(7):258-64.

9. Brown JS, Grady D, Ouslander JGA, Herzog AR, Varner, RE \& Posner SF. Prevalence of urinary incontinence and associated risk factors in postmenopausal women. Obstet. Gynecol. 1999; 94:66-70.

10. Resnick NM, Yalla SB \& Laurino E. The pathophysiology of urinary incontinence among institusionalized elderly persons. N. Engl. J. Med. 1989; 320(1):1-7.

11. Grimby A, Milsom I, Molander U, Wiklund I \& Ekelund $P$. The Influence of urinary incontinence of the quality of life of elderly women. Age and Ageing. 1993; 22:82-9.

12. Wu C-Y, Su T-P, Fang C-, L \& Chang MY. Sleep quality among community-dwelling elderly people and its demographic, mental, and physical correlates. Journal of the Chinese Medical Association. 2012; 75:75-80.

13. Cohen-Zion $M$ \& Ancoli-Israel $S$. Sleep disorders. Dalam: Hazzard WR, Blass JP, Halter JB, et al, editor 
(penyunting). Principles of geriatric medicine and gerontology. Edisi ke-5. New York: Mc Graw-Hill Companies, Inc; 2003. hlm 1531-41.

14. Tyagi S, Perera S, Clarkson BD, Tadic SD \& Resnick NM. Nocturnal polyuria in older women with urge urinary incontinence: role of sleep quality, time in bed, and medications used. J. Urol. 2016. DOI: 10.1016/ j.juro. 2016.09.080. 